\title{
Professionalising positive psychology: Developing guidelines for training and regulation
}

\author{
Tim Lomas · Itai Ivtzan
}

\begin{abstract}
Although positive psychology (PP) was initially conceived as more a shift in perspective (towards the "positive") than a new field per se, in pragmatic terms, it is arguably beginning to function as a distinct discipline, with people self-identifying as "positive psychologists." Thus, we contend it is time for the field to start developing a system of professional (e.g., ethical) guidelines to inform the practice of PP. To this end, we outline one such possible system, drawing on guidelines in counselling and psychotherapy. Moreover, we argue for the creation of two tiers of professional identity within PP. Firstly, people with a master's qualification in PP might label themselves "positive psychology practitioners." Secondly, we raise the possibility of creating a professional doctorate in PP which would enable graduates to assume the title of "positive psychologist." We hope that this paper will contribute towards a dialogue within the field around these issues, helping PP to develop further over the years ahead.
\end{abstract}

Keywords: positive psychology, ethical practice, reflective practice, regulation; accreditation

\section{Introduction}

It is now almost 20 years since the emergence of positive psychology (PP). In that time, the field has gone from strength to strength. For instance, a wealth of literature has been generated, with over 18,000 papers identified by Rusk and Waters (2013) as pertaining to PP. Most saliently, in the context of the present paper, there is an extensive offering of PP courses across the globe, at all educational levels, including at least 12 postgraduate master's programmes in applied positive psychology ('MAPP' courses). Applied PP is 'the application of positive psychology research to the facilitation of optimal human functioning' (Linley \& Joseph, 2004, p. 4). As such, according to Aristotle's (350 BCE) classification of human activities - poiēsis (productive and/or creative disciplines) theōria (the pursuit of knowledge) and praxis (practical disciplines) applied PP might be regarded as a form of praxis, defined as "practical action informed by theory" (Foster, 1986, p. 96). Students on such courses learn to apply PP in real-life settings, for example, through PP interventions (PPIs), i.e., activities or practices designed to improve wellbeing (Parks \& Biswas-Diener, 2014).

These developments are, of course, all hugely welcome, and are testament to the enthusiasm and excitement that the field has generated, and, indeed, the personal, professional and academic needs that it has fulfilled. However, the speed and extent of these developments has generated a significant potential problem: the field is, as yet, essentially unregulated as a whole. This means that there are no agreed standards or formal guidelines concerning how PP should be used in real-life settings. This lack of regulation is the issue that this paper seeks to highlight, and to suggest some possible solutions to. It must be emphasised that these are not the only possible 
solutions, and we are not aiming to be prescriptive or dogmatic in our recommendations. Rather, the aim is to float some potential responses to these issues, thereby contributing to a dialogue around ethics and regulation - already set in motion by leading figures in PP, such as Handelsman, Knapp, and Gottlieb (2009) and Vella-Brodrick (2011, 2014) - thus assisting the ongoing development of the field. These earlier works have made valuable suggestions around the kind of ethical principles that should be at the heart of best practice within PP; for instance, Vella-Brodrick (2014) highlights the importance of integrity, industriousness, innovation, and impact. Building on such ideas, the current paper offers a number of suggestions for how such principles might be instantiated in practical terms.

The paper comprises a number of sections. First, we outline the reasons why we feel PP constitutes a distinct field that needs regulation, and then discuss why it might be helpful, and, indeed, necessary, to "professionalise" the field. Next, we introduce the notion of ethics, and explain why PP would benefit from an ethical framework to guide its practitioners. We then introduce the ethical framework of the British Association of Counselling and Psychotherapy, since we feel that this is a set of guidelines that PP could adopt or at least adapt (though we recognise that there are other similar frameworks that could be drawn on). Following that, we introduce two practical structures that might be of help in upholding an ethical framework, namely, supervision and reflective practice. Finally, we discuss some possible suggestions for professionalising the field. This includes: (a) creating a non-accredited professional identity of a "positive psychology practitioner" for graduates of MAPP courses (as well as hybrid MAPP courses, such as the MSc in Applied Positive Psychology and Coaching Psychology at the University of East London); and (b) proposing a new accredited doctorate in positive psychology, leading to a status as a "positive psychologist."

\section{Is PP a field?}

Before we discuss the need to professionalise PP, we must answer the claim that PP isn't a distinct "field" at all. After all, the nature of PP has always been a grey area. Many original proponents of PP argued that it is not a new speciality within psychology, but rather a "collective identity," unifying researchers interested in "the brighter sides of human nature" (Linley \& Joseph, 2004, p. 4). From this perspective, PP is simply an ethos, a way of "leaning towards" positive topics that is open to scholars and practitioners in established psychological fields, from clinical psychologists (e.g., Wood \& Tarrier, 2010) to neuroscientists (e.g., Urry et al., 2004). This identity served to unify disparate scholars already working on topics that are now regarded as falling within the purview of PP, like positive emotions or psychological development. However, we contend that PP is indeed becoming a distinct field in psychology for the simple pragmatic reason that many people - including some graduates of MAPP courses - are beginning to call themselves, rightly or wrongly (from a regulatory perspective), "positive psychologists." Given that "psychologist" is a protected title in most jurisdictions across the world, requiring doctoral level training and accreditation, the use of such a title is problematic. As such, the proper use of "positive psychologist" is one of the issues this paper will address. However, its current usage does substantiate our point here that PP is a distinct field, since many people are beginning to claim and use it as a professional identity.

In recognising PP as a distinct field, this does not mean that it cannot also be just an "ethos" for psychologists in other disciplines; clinical psychologists who embrace PP will still be clinical psychologists, for instance (Wood \& Tarrier, 2010). For such people, regulation is not an issue, as they will be guided and regulated by codes of practice, and accredited by professional bodies, in their own fields. However, we must also recognise that, for many people, such as MAPP 
graduates without a background in a professional area, PP is a speciality and a professional identity in its own right. Of course, the question of exactly where we delineate the "territorial boundary" for PP - how we demarcate it from such kinship fields as clinical psychology and psychotherapy - is a complex question, and will be an issue for debate over the coming years. Likewise, there is a lively debate around the necessary and sufficient criteria for identifying an intervention as a PPI (Parks \& Biswas-Diener, 2014). In this respect, one possible point of demarcation could be that whereas fields such as clinical or counselling psychology are concerned with enhancing wellbeing in clinical settings/populations, PP focuses on the promotion of wellbeing in non-clinical settings/populations, such as the workplace or in schools. This would of course not prevent PP being used in clinical settings, as per Wood and Tarrier's (2010) notion of "positive clinical psychology." Nevertheless, as a broad generalisation, it does carve out a particular useful and important role for PP. For instance, whereas a person in distress might currently turn to a clinical or counselling psychologist, in future, a manager of a workplace looking to enhance employees' wellbeing could call upon a positive psychologist. We do not have a definitive answer for demarcating PP: this is a topic of ongoing debate, and practitioners in the field may define this in varied ways. However, even as we can and must continue to debate such issues, the fact remains that, from a pragmatic perspective, people are currently selfidentifying and practising as positive psychologists. As such, the lack of professional regulations or guidance for such people is arguably an issue.

\section{Professionalising PP}

Of course, most people applying PP in real-life settings (e.g., delivering PPIs within the workplace) may well be doing so in ways that are sensitive, responsible, and ethical. However, this does not mean that PP is nowhere being practised without issues. Saying that is not to impute malign motives to practitioners in such cases. Rather, it is simply to suggest that, for a variety of reasons - such as inexperience or a relative lack of ethical protocols - "best practice" may not always be followed. Thus, this paper sets out the case for introducing an element of professionalism into the practice of PP. In so doing, PP is arguably tracing a comparable journey to that undertaken by kinship applied disciplines. For example, in previous decades, counselling and psychotherapy have been (and still are) engaging with the same types of issues that we are raising here, including questions of who has the "right" to practice, and how high standards can be upheld (Belloch, 1997). As such, we outline one potential vision for what a more regulated PP might look like, and advocate for some professionalization of PP, and for the creation of a specific professional identity for people who use/practice PP.

More specifically, we suggest that two tiers of professionalization could be created: (a) "positive psychology practitioner" (a non-accredited professional identity), and (b) "positive psychologist" (an accredited psychological profession). With the former, this simply gives a label to what is already currently happening, i.e., the application of PP in real-life settings, e.g., by graduates of MAPP courses. For these people, we recommend that they use the title of PP "practitioner." We envisage this being a label someone could use on the basis of having completed master's level study/training in PP. This could make it similar in standing to a master's in counselling, for instance, i.e., sufficient to practise counselling, and to be called a "counsellor," but not sufficient to use the protected title of "psychologist" (which requires a professional doctorate in counselling psychology). With the second tier, this refers to the more ambitious future aim of establishing "positive psychologist" as a distinct psychological profession (comparable to professional identities such as "counselling psychologist" or "educational psychologist"). This would require professional doctorate level training, featuring 
elements such as professional skills training, work placements (e.g., in organisations), and practical mentoring/supervision, as per professional psychology doctorates, such as clinical psychology. (This would stand in contrast to purely research-based PhDs related to PP, which, like in any other domain of psychology, do not - and in future still would not - confer any accredited ability to practise PP per se.) One such doctorate training course already exists (at Claremont University). However, given the current enthusiasm for people using the term "positive psychologist," we would argue that a more widespread and systematic creation of doctoral courses is both (a) warranted (i.e., they would be well-subscribed) and (b) necessary (i.e., if people are already adopting the title of "positive psychologist," there should be training, regulation and accreditation to match).

Pertaining to the latter point, a crucial aspect of the proposed notion of a "positive psychologist" is that it would involve recognition by a relevant professional body, leading to chartered status as a psychologist. We would anticipate that this recognition would need to be granted by the relevant professional body in each country, such as the British Psychological Society in the UK, or the American Psychological Association in the USA. However, we would also envisage a role for either of the main existing PP bodies - or, ideally, both, working in collaboration - namely, the International Positive Psychology Association (IPPA) and/or the European Network of Positive Psychology (ENPP), who would be able to guide and advise these national bodies, and ensure consistency across jurisdictions.

Should these developments come to fruition, in future, any person or organisation concerned with increasing wellbeing in a non-clinical context could ideally turn to a chartered positive psychologist (possibly in the first instance), or alternatively to a PP practitioner. That is, in practical terms, while both tiers of people would be able to "practise" PP, one might speculate that differences would inevitably emerge regarding professional opportunities and remuneration prospects. As with any other form of tiered qualification (e.g., an MSc versus a $\mathrm{PhD}$ ), those possessing the higher qualification might find their services in greater demand, and would likely be able to command higher fees, or obtain more prestigious or demanding appointments, etc. accordingly.

The following sections explore what it could take for a person to be recognised either as a PP practitioner or a positive psychologist. Essentially, we are asking what kind of skills and qualities would we want PP professionals - an overarching label for both PP practitioners and positive psychologists - to have, and how best can we ensure that they do? So, how can we answer these questions? One way is to turn to applied psychological disciplines that have already developed a high level of professional maturity, such as clinical or counselling psychology, and to learn from these, which is what we shall do here. In particular, we will draw upon systems of ethics that have been developed in these fields, which not only outline people's responsibilities as applied practitioners (e.g., duties of care), but which also articulate personal and professional standards that such people should aspire to. Before we introduce these ethical frameworks, though, we need to clarify what ethics are.

\section{What are ethics?}

To understand what ethics are, it helps to conceptualise two similar constructs: values and morals. Values are "desirable goals, varying in importance, that serve as guiding principles in people's lives" (Sagiv \& Schwartz, 2000, p. 178). Values are thus not necessarily about good/bad or right/wrong, but are "conceptions of the desirable" that drive behaviour and motivate life choices (Schwartz, 1999, p. 24). In contrast, morals are explicitly about "notions of right and wrong" (Hazard Jr, 1994, p. 451). However, there is an intimate relationship between values and 
morals, since values held in common in a society often become the basis for a more explicitly codified moral framework. The word "morals," which derives from the Latin mores, signifies "usage in a community," or, more specifically "customs or usages of social life sanctioned by the conscience of the community" (Muzzey, 1906, p. 29). Ethics then is the explicit codification of a system of morals, in which these are communally defined and recognised. The term derives from the Greek ethikos, meaning "custom or usage," and refers to norms that are "shared by a group on the basis of mutual and usually reciprocal recognition" (Hazard Jr, 1994, p. 453).

Moreover, of particular relevance here is the idea of domain-specific systems of ethics. This includes the regulation of professional disciplines, such as clinical psychology, where ethics refers to "rules and standards of conduct recognised as binding in a professional body or an association" (Mathenge, 2013, p. 9). Most established professions have formal ethical codes, articulating how people in that profession should act. Such codes involve "ethical statements" that are used as a way of explaining how work in the field is "best undertaken to achieve the greatest good and minimise any potential wrongs" (Mitchels \& Bond, 2010, p. 5). For example, medicine, law and psychotherapy share in common two ethical precepts: client-practitioner confidentiality and record keeping. Confidentiality is recognised as a human right of those seeking the service of such professionals, and must be respected to protect such people, and to facilitate a professional relationship based on trust and openness (Gallagher \& Hodge, 2012). Record keeping is likewise vital if the practitioner is to provide consistent service, taking into account all the relevant elements of the treatment (Jenkins, 2007). Record keeping may also be important for other reasons: for instance, in many professions, practitioners may be required to give evidence in a court of law (Soisson, Van de Creek, \& Knapp, 1987). These ethical protocols are not only recognised as standards for good practice, but are upheld through various mechanisms, including being embedded into the training and accreditation of these professions, and monitored by regulatory bodies.

\section{The need for an ethical framework}

So, where does PP presently stand in terms of a formal, agree-upon ethical framework? Unfortunately, it does not currently have one. Of course, that is not to say that practitioners using PP are necessarily unregulated or operating unethically. As discussed above, many people using PP will be affiliated to professions that have their own ethical standards, including psychological professions (e.g., clinical psychologists), and other professions, such as teaching or nursing. Similarly, on MAPP courses, students are usually required to adhere to ethical guidelines and to obtain approval from ethical committees when undertaking research. Thus, many practitioners of PP will already be guided by ethics protocols within their own discipline and/or academic setting, which means PP is already being practiced ethically - in a formally regulated and/or accredited way - in many instances. However, as argued above, there will also be people who are not in established professions, or currently undertaking a MAPP course, who may be offering services under the (currently contentious) label of a "positive psychologist," e.g., delivering PPIs within an occupational setting. Under such circumstances, while most such people may well personally be decent and ethical, there is no guarantee that they will be practising ethically in a formal, systematic way. As such, we feel that it is important that PP collectively instantiates a system of ethical guidelines that such people can and arguably should follow in order to maintain best practice. This ethical code could then be used to guide PP practitioners (in a non-binding, non-mandatory way), and to regulate positive psychologists (in a binding, mandatory way). That is, we suggest that PP "practitioners" - e.g. MAPP graduates - can be encouraged to follow this ethical code, but cannot necessarily be compelled to adhere to it, since they are not an accredited 
profession per se. However, for future positive psychologists - who can be trained and accredited through the creation of doctorate level training programmes - adherence to this code could be mandatory, and a condition of being accredited.

In some ways, PP is already moving towards a situation where a centralised body provides guidance and even regulation around ethical issues. The main professional body that currently oversees PP activity is the IPPA, which offers its members information and support, including teaching programmes, PP resources, conferences, and various research divisions. It also has an ethics committee that makes decisions relating to the conduct of the association and its members. However, as yet, neither the IPPA nor any other PP body has issued an ethical framework to which its members must commit in order to be recognised by or affiliated to that body. As such, we contend that PP can learn from other similar associations, and create an ethical code suited to its aims and purposes. As noted above (and discussed further below), such guidelines could be created by either the IPPA or the ENPP (or, ideally, both in collaboration). These guidelines could then be passed to local national bodies (e.g., the British Psychological Society), who could adopt or adapt these guidelines, according to preference, and thus regulate the field in their particular national territory. Specifically, we suggest that PP could be guided by the fields of counselling and psychotherapy, which similarly involve working with groups and individuals to enhance their wellbeing. Indeed, there is already a close overlap between PP and these fields through the emergence of initiatives like positive psychotherapy (Seligman et al., 2006) and wellbeing therapy (Fava \& Ruini, 2013). In the next section, then, we explore the ethical systems that have been developed within counselling and psychotherapy, and then examine how PP might learn from these more established fields.

\section{Learning from counselling and psychotherapy}

Compared to PP, counselling and psychotherapy are well-established professional fields. In the UK, there are two main associations encompassing these: the British Association for Counselling and Psychotherapy (BACP) and the United Kingdom Council for Psychotherapy (UKCP). In past decades, counselling and psychotherapy have been (and still are) on comparable journeys to that being embarked upon by PP, asking similarly fundamental questions around the nature of their discipline, including who has the "right" to practise it, and how high standards in practice can be upheld. The regulation of counselling and psychotherapy is an ongoing topic of debate within these fields; indeed, some practitioners disagree with the very idea of regulation (Gabriel, 2009). Nevertheless, these bodies have established frameworks to protect clients and practitioners. Given the strong overlap between PP and these fields, as elucidated below, rather than reinventing the wheel, we feel that PP could simply adopt the ethical frameworks used in these fields. Their frameworks constitute comprehensive and rigorous sets of guidelines that have been developed, applied, examined and strengthened in the heat of real-life practice over a number of years. As such, it is our contention that PP does not need to start from scratch, but can import wholesale their guidelines (while perhaps also adding to them, if desirable). This is not simply a matter of expediency, but a question of deep professional kinship between PP and counselling and psychotherapy, sharing common roots in humanistic psychology (Resnick, Warmoth, \& Serlin, 2001). Moreover, it is also a case of professional respect, with PP learning from and emulating its "older and wiser" psychological cousins.

So, what kind of ethical frameworks are there in counselling/psychotherapy? The BACP's (2010) set of ethical rules - which we shall draw upon here - is entitled the Ethical Framework for Good Practice in Counselling and Psychotherapy. Of course, national bodies in other territories have developed their own ethical frameworks, such as the American Psychological 
Association's (2010) Ethical Principles of Psychologists and Code of Conduct. While such frameworks have substantial overlaps with the BACP's, they may have additional components that might also be helpful to PP. For instance, the APA's code has guidance around the need to be careful in relation to engagement with the media, which is not specified in the BACP framework. As such, if the IPPA/ENPP were to develop a set of ethical guidelines for PP - as advocated here - it may be the case that they draw upon more than one framework. On the other hand, if, as anticipated here, the actual regulation of PP is undertaken by national bodies, it may be the case that such bodies will simply seek to apply the ethical codes that have already been developed in their territory; thus, for instance, in the USA, the APA may well prefer to simply instantiate their 2010 framework. Nevertheless, for the purposes of this paper - i.e., stimulating a discussion around ethics in PP - it will suffice to present one viable example of an ethical code which may be relevant to the field, which, in this case, will be the BACP framework. It encompasses three dimensions: values, principles, and personal moral qualities. We can consider these in turn. Firstly, in terms of values, the framework holds that practitioners should be committed to:

- Respecting human rights and dignity

- Protecting the safety of clients

- Ensuring the integrity of practitioner-client relationships

- Enhancing the quality of professional knowledge and its application

- Alleviating personal distress and suffering

- Fostering a sense of self that is meaningful to the person(s) concerned

- Increasing personal effectiveness

- Enhancing the quality of relationships between people

- Appreciating the variety of human experience and culture

- Striving for the fair and adequate provision of counselling and psychotherapy services

It is hard to imagine anybody who is currently applying PP in practical contexts objecting to any of these values. Indeed, these values relate closely to a number of constructs and outcomes that are at the heart of PP. For example, the idea of fostering a meaningful sense of self is central to theories of wellbeing, such as Ryff's (1989) model of psychological wellbeing. Likewise, increasing personal effectiveness is aligned with constructs like self-determination (Ryan \& Deci, 2000). Or again, enhancing the quality of relationships between people is central to many PPIs, such as family-centred positive psychology (Sheridan et al., 2004). Thus, already we can see it would not be too much of a leap for PP to incorporate ethical principles such as these.

The second dimension of the BACP (2010) framework is "principles." Here, the values listed above are the foundation for various action-oriented principles which outline the main ethical responsibilities of the counselling/psychotherapy practitioner:

- Trustworthiness: respect for the trust placed in the practitioner (also referred to as "fidelity"). Strict client-practitioner confidentiality is an important aspect of this trust. Practitioners must also honour any agreement with the client.

- Autonomy: respect for the client's right to self-determination. The practitioner must provide accurate information, obtain the client's informed consent, and emphasise the voluntary nature of their participation. This principle is designed to minimise the manipulation of clients.

- Beneficence: commitment to promote the client's wellbeing. This principle prescribes acting in the client's best interest, based on a professional assessment. One should work strictly within one's limits of competence, and only provide services based on adequate and relevant 
training and experience. One's practice should also be backed up by scientific research and systematic reflection.

- Non-maleficence: commitment to not harming the client. The practitioner must avoid any sexual, financial, emotional or other abuse and mistreatment of the client, and also not offer services in a state of incapacitating illness or other adverse personal circumstances.

- Justice: fair and impartial treatment of all clients, and provision of adequate services. This principle underscores the practitioner's legal obligations, and their commitment to not discriminating against any clients (or other individuals/groups).

- Self-Respect: fostering the practitioner's self-knowledge and self-care. Practitioners should also apply the principles above to themselves, and seek therapy and other paths of personal development. Supervision, discussed further below, is part of this principle.

As with the values above, it is hard to imagine anyone studying or practising PP objecting to any of these principles. Some are already at the heart of PP, especially beneficence, which mirrors Lomas, Hefferon and Ivtzan's (2014, p. ix) definition of PP as "the science and practice of improving wellbeing." Likewise, other principles relate closely to constructs within PP, such as the principle of autonomy, which is coterminous with the concept of self-determination (Ryan \& Deci, 2000). Other principles resonate with PP values, but in this context are somewhat legalistic, and so have hitherto not explicitly been formalised within the field. For example, although most PP practitioners would surely implicitly recognise and uphold the principle of justice, an explicit commitment to this is currently not required of practitioners. In putting PP on a more secure professional footing, this is the kind of principle one would want to see actively recognised. The final quality, self-respect, is also particularly intriguing. While many PP practitioners arguably already take a keen interest in their own wellbeing and development, this principle makes this an explicit part of professional practice, as discussed further below in the section on reflective practice.

Finally, the third dimension of the BACP's (2010) ethical framework is "personal moral qualities." This refers to the professional's personal character that binds together all the other values and principles. While it may be arguably unrealistic to expect a person to fully embody all the qualities listed below, nevertheless, counsellors/psychotherapists are encouraged to recognise the value of these, and be guided by them. One may be struck by the overlap between these qualities and the strengths outlined in the VIA taxonomy (Peterson \& Seligman, 2004). This reinforces the point that all these ethical guidelines are already familiar territory for PP. The introduction of an explicit ethical framework in PP would simply formally recognise the value of PP professionals upholding these desirable qualities and processes. The BACP moral qualities are:

- Empathy: the ability to communicate understanding of another person's experience from that person's perspective

- Sincerity: the commitment to stand behind one's words

- Integrity: the commitment to be honest and straightforward in dealing with others

- Resilience: the capacity to withstand being involved with the concerns of others without being personally affected by these issues

- Respect: the ability to respect other people and the way they understand themselves

- Humility: the ability to accept and acknowledge one's strengths and weaknesses

- Competence: effective deployment of the skills and knowledge required for the task at hand

- Fairness: the consistent application of appropriate criteria in taking decisions and actions

- Wisdom: sound judgment and informed practice 
- Courage: the capacity to overcome fears, risks and uncertainty

In counselling and psychotherapy, these ethical guidelines are not simply articulated, but structures are in place to help trainees and practitioners cultivate and uphold these, such as supervision and reflection, as the next two sections outline.

\section{Supervision}

Principal among the structures in place to help counselling and psychotherapy trainees develop ethically is a process of supervision, where a practitioner's work is monitored and supported by an experienced colleague. Such supervision has a number of goals (Inskipp \& Proctor, 1993). The first is formative: to enrich the practitioner's education, training and skill, with a view to enhancing the quality of their work. For instance, one method used in this regard involves roleplaying based on client material. The second goal is normative. The supervisor directs the practitioner in following ethical guidelines, maintaining adequate standards, and observing boundaries. The third and final goal is restorative. Not only does supervision maintain and empower the implementation of values, principles, and personal qualities, it also provides the practitioner with a support system. Thus, in a more pastoral sense, supervision is one answer to the important question of "who will care for the carers?" People working in caring professions are themselves in need of care and support to help them cope with the demands of their work and to attain a healthy and balanced life more generally. Without this, workers may struggle to help others effectively, and can even experience burnout (Leiter \& Maslach, 2005). Thus, a helpful and caring supervisor can offer invaluable support.

The BACP ethical framework suggests that all practitioners should participate in regular supervision. Currently, there is no such model of supervision in the field of PP. However, as with the values/principles above, the idea of supervision resonates with the ethos of PP. Indeed, not only could PP benefit from incorporating supervision principles and practices, but the practice of supervision itself can, in turn, learn from PP, as demonstrated by the emergence of a new branch of supervision based explicitly on PP, namely Strengths-Based Supervision (Edwards, 2012; Wade \& Jones, 2013). This model uses Peterson and Seligman's (2004) work on strengths to enhance supervision, reframing the process in a way that capitalises on the supervisee's strengths. For instance, Edwards (2012) outlines various ways to harness strengths in supervision, including: enhancing optimism, empowering supervisees to realise that they are capable of healing others, helping supervisees develop self-efficacy, supporting them in applying their strengths, and encouraging them to invite clients to engage in a similar way. This is a classic PP approach to clinical work, and offers a transformative attitude to supervision. In PP itself, though, currently, the only type of formal supervision occurs in the context of academic research; e.g., students taking MSc MAPP courses have an academic supervisor to guide them through their research dissertation. However, one can see the value of all PP practitioners being able to access supervision, particularly a deeper supervisory relationship that safeguards and promotes their wellbeing and personal development.

\section{Reflective practice}

A second key factor in place to help counselling/psychotherapy practitioners develop as professionals - which PP can also learn from - is the notion of reflective practice. This means reflecting on the quality of one's work, and also, in a deeper sense, on one's own wellbeing, and on one's personal and professional development. In that latter respect, the importance of reflective practice is embodied in ethical principles such as self-respect, as outlined above. One might identify three main "levels" of reflective practice, constituting three sequentially deeper 
forms of reflection: on one's particular actions, on one's career and practice of PP generally, and, finally, on one's life journey as a whole. We will take these in turn.

Firstly, in an immediate sense, we can reflect on our current actions and thoughts. An influential model in this respect, especially in the context of professional practice, is Schön's (1983) notion of the "reflective practitioner." Schön identifies two key forms of reflective practice: reflection-in-action and reflection-on-action. The former means trying to be aware in the moment of how we are affecting a situation or are being affected by it; this involves "on-the-spot surfacing, criticising, restructuring, and testing of intuitive understandings of experienced phenomenon" (p. 241). The latter means reflecting on one's actions in retrospect, after the event. These two processes reinforce each other, with both serving to develop one's professional practice. For example, take the case of a PP practitioner delivering a PPI. Reflection-in-action means paying attention to the dynamics of the interaction as it is happening, e.g., the practitioner might reflect on how clearly they are introducing and explaining the PPI. Afterwards, the practitioner can reflect on how well it went, and also how they might improve next time. This model of reflective practice has been applied across disciplines, from clinical psychology (Cushway \& Gatherer, 2003) to social work (Gardner, 2001) to teaching (Korthagen \& Vasalos, 2005). A useful way to think about reflective practice is that it means combining applied science with artistry (Schön, 1983). Applied forms of science - of which we include PP - to an extent revolve around skills that could, if practised poorly, be used in a somewhat mechanical way. However, what elevates a practitioner is being able to apply such skills with the creativity, selfawareness, and care that we associate with people engaged in artistic pursuits.

In terms of facilitating this kind of reflection, training courses for therapists or clinical psychologists endeavour to teach reflective practice to their trainees (Guiffrida, 2005). As with ethics, PP can learn from such fields and apply practices that they have developed, many of which are already at the heart of PP. For example, in counselling/psychotherapy, a key activity for helping practitioners become more reflective is mindfulness (Shapiro et al., 2007). Indeed, mindfulness is conceptually similar to reflection and aspects of reflexivity; for example, Finlay and Gough's (2003, p. ix) definition of reflexivity as an "immediate, dynamic and continuing selfawareness" would serve equally well as a definition of mindfulness. Mindfulness is being incorporated into training in many professions, including counselling (Shapiro et al., 2007), medicine (Irving et al., 2012), nursing (Mackenzie, Poulin, \& Seidman-Carlson, 2006), teaching (Napoli, 2004) and even law (Riskin, 2004). It has also been incorporated into some PP practices and interventions (Ivtzan \& Lomas, 2016), making it highly relevant to the development of PP. As such, we would encourage PP courses to incorporate mindfulness into their teaching structures, as elucidated further below.

Beyond reflecting on particular actions/experiences, professionals can also reflect in a longerterm way on how their practice is developing generally. This is more an overarching assessment of how one is changing and hopefully evolving in one's career over time. Ideally most people would engage in this type of reflection anyway, without specific inducements to do so, whatever occupation they were in. However, as with ethics, professions such as counselling and psychotherapy have also built up structures to encourage this kind of reflection, such as supervision (Edwards, 2012). Moreover, there are specific models of reflection that practitioners can engage in to promote long-term development. One such model is Korthagen and Vasalos's (2005) five-stage ALACT framework. The first stage is Action (e.g., delivering a PPI). Next is Looking back, i.e., reflection-on-action. The process continues with Awareness of essential aspects, where the practitioner analyses the impact of the tools/techniques chosen. In the fourth stage, Creating alternative methods of action, the practitioner considers other possible strategies 
that could enhance future interventions. Finally, in the fifth stage, Trial, the practitioner applies the adaptations or changes that were identified in the previous stage, and examines the consequences. Together, these stages generate an ongoing cycle of reflection that facilitates continual professional development.

Moreover, the kind of reflection prompted by the ALACT framework may not only enhance one's professional performance, but can lead to deeper, more personal reflections on one's self, thereby empowering self-growth. In Korthagen and Vasalos's (2005) model, there are not only stages, but six progressively deep and personal levels of reflection. The most superficial level is reflection on the environment: the practitioner reflects on everything they encounter "outside" themselves, like the client's actions. At a slightly deeper level, the practitioner considers the ongoing dynamics of the practitioner-client dyad (the nature of their interaction). Deeper still, the practitioner can focus on their own competence: the knowledge/experience they possess to handle the situation. Going further "in," the practitioner can contemplate the underlying beliefs which influence his or her actions (with parallels to Seligman's (1990) notion of "icebergs"). Underneath this, the practitioner can consider their professional identity, i.e., what kind of person are they becoming in the context of their work. Finally, at an even deeper existential level, the practitioner can reflect on their life "mission". Also known as the "level of spirituality" (Dilts, 1990), this last level is a reflection on the very nature of one's being, a more fundamental enquiry into the nature of one's life and the journey one is on, into what gives meaning and significance to one's life.

Thus, at its deepest level, reflection involves "a personal journey of reflective sense-making" (Waddock, 2011, p. 177); this can be a process that touches the core of who practitioners are as people, and can engender transformative personal change in the practitioner. In reflecting in a deeper sense on their life journey, practitioners can contemplate the path they have taken so far, and consider where they stand now. However, the future lies over the horizon: the great unknown. As such, practitioners' potential for transformation may be hidden to themselves; almost by definition, the person they may become in future is essentially unknown to their present selves. Thus, change derives from inner potentials of which the person may be only dimly aware. An intriguing way to consider this process of change is the "Johari Window" (Luft, 1969), a 2-by-2 schematic which illustrates aspects of ourselves that are known or unknown to us and to others. Aspects that are known to us and to others are our persona, our clear and visible "character." Aspects that are known to us but unknown to others are our "masked features," dimensions of the self that we conceal from others. Aspects that are known to others but unknown to ourselves are our "blind spots." Finally, there are aspects of the self that are unknown to others and to ourselves, dimensions of the self that have not yet been brought to light. This last dimension is particularly important, being regarded as the main "source" of personal growth and development (Luft, 1969). Although this dimension is elusive, practitioners can help bring it into the light through practices of reflection, such as meditation. These practices can be vehicles for self-discovery, shining a light of self-awareness on practitioners' hidden potentials and encouraging these to grow and flourish. Thus, ultimately, developing a system of ethical guidelines - including reflective practice - is not just a matter of striving to safeguard the wellbeing of clients. It is also a way of encouraging the professional, and, moreover, personal development of PP professionals themselves.

\section{Conclusion: Practical recommendations}

So, we have suggested that PP might do well to adopt an ethical framework, and, moreover, that PP could adopt/adapt the framework developed by the BACP (2010) for the fields of counselling 
and psychotherapy. Of course, many people studying and practising PP may already be embodying and upholding these kinds of values and principles. However, as we have suggested, PP might benefit from a more systematic and explicit ethical framework to guide all those practising PP, in whatever context. We have also suggested that PP courses could further instantiate or augment structures that help in the inculcation and maintenance of professional practice, such as supervision and reflection. As such, we shall finish this article with some practical recommendations of how we might progress from here, and how we can put PP on a more professional footing. Again, we emphasise that the following recommendations are not so much for people using PP theories or practices in existing professions, such as clinical psychology or education, as these people will already have a professional standing. Rather, it is for people who are not affiliated to a particular profession - such as some graduates of MAPP courses - but who wish to practise PP in real-life settings. We shall firstly consider the case of PP practitioners (as such people essentially exist already), and then positive psychologists (as the creation of this profession is a future goal).

Firstly, "positive psychology practitioners" is the term we are suggesting for people who have obtained a master's level qualification in PP. Being only a master's qualification, this means that such students cannot be labelled as professional psychologists, for which doctorate level training and accreditation is required. However, the term "practitioners" does serve to create a professional identity for such graduates, and to give them a badge of recognition. Since this would not be an accredited professional identity, such people could not necessarily be compelled to adhere to a formal PP code of ethics, like the BACP code, which is one framework we are suggesting that PP could adopt. However, this code could simply be in place as a guiding model - promulgated by the IPPA and/or the ENPP - which such students could be encouraged to adhere to.

This encouragement could be formalised by the incorporation of ethical/professional training into PP master's courses. At a minimum, we recommend that such courses devote one twelfth of their teaching content to the teaching of ethical/professional practice. For instance, in the UK, a master's course typically involves 180 credits worth of modules. This would mean that such courses would ideally include one 15-credit module devoted to ethical/professional practice. Such courses could also include the other supporting elements of ethical/professional practice outlined above, such as supervision and reflection. With supervision, on MSc courses, students already have a supervisor, in any case, to assist them in undertaking research projects. The role of such supervisors could therefore be expanded to take on the more professional and pastoral role that supervision has in counselling and psychotherapy. With reflective practice, this could likewise be encouraged in the context of the supervision relationship. Such courses could also feature sessions on reflective practices, such as mindfulness - not simply in a theoretical pedagogical way, but in the form of experiential sessions in which students are encouraged to learn and practise mindfulness themselves.

As to the legal and professional status of such practitioners, some such graduates will already be affiliated with another profession (e.g., being a qualified teacher or nurse), and so will be governed by the regulatory frameworks in these professions. However, some graduates will not be in any such profession (e.g., students who have undertaken a MAPP course immediately after an undergraduate degree). The professional status of such graduates is currently vague - which, indeed, is one of the very reasons for this paper - a situation that is clearly not ideal. Moreover, even if such people become labelled as PP "practitioners," as advocated here, their status would remain somewhat vague. However, provided that these graduates do not use the protected term of "psychologist," there is nothing necessarily preventing them from using their PP expertise in 
a consulting capacity (e.g., advising a company on how to improve the wellbeing of its workers). As such, in pragmatic terms, one possible avenue for clarifying the status of such practitioners would be for them to be regarded as essentially taking on a consulting role, broadly defined. In so doing, such practitioners would arguably be on similar territory - ethically and professionally - to the millions of other people worldwide who similarly offer their services as "consultants" in some capacity. (Thus, of course, such practitioners would likewise need to ensure that they abide by the laws/regulations in the country in which they are working.) Moreover, by standardising their identity as a PP "practitioner," this would provide a rudimentary "kite-mark" regarding their professional skills (e.g., compared to someone without a MAPP qualification who is nevertheless presenting themselves as a PP "consultant"). This would allow organisations seeking to avail themselves of the services of such practitioners to at least have some assurance of quality.

More ambitiously, we are also advocating the creation of professional doctorate level training in PP, enabling graduates to be officially recognised as "positive psychologists." In our opinion, it would be desirable for this doctorate to not only be open to students with a psychology undergraduate degree. One of the strengths of many MAPP courses is that their admission criteria do not require this type of degree, which means they are able to admit students from a range of backgrounds, from business to public health. As well as widening access to MAPP courses, these more open entry requirements ensure a diverse student cohort, which adds to the richness and depth of students' learning experience. We would ideally like to see this inclusivity extended to PP doctorate training. However, we also recognise that, for students without a background in psychology, some additional pre-entry training courses may be necessary to equip them with certain skills that are acquired on undergraduate psychology courses, such as proficiency in statistics.

Essentially, this doctorate training would mean providing an extended version of the MAPP programme, in line with the training for professional psychological qualifications, such as clinical, counselling, or educational psychology. In the UK, this would generally mean a fouryear training programme, although the length of training may vary in other countries. For instance, in the UK, the Quality Assurance Agency for Higher Education (2008) states that doctoral level qualifications should comprise a minimum of 540 credits (versus 180 for a master's level qualification), which is a minimum of three times the length of a MAPP course. On such courses, the new ethical/professional elements introduced into MAPP, as outlined above, could be expanded and deepened accordingly. For instance, if MAPP courses in future include a 15credit module on ethics/professional practice, then the doctoral programme would ideally have a 45-credit module devoted to this. Likewise, in terms of supervision, the more intense doctoral supervision provided by a three to four-year course would enable students to develop a concomitantly deeper supervisory relationship. Moreover, as with counselling and psychotherapy, one would anticipate graduates maintaining an ongoing supervisory relationship in some form post-graduation. Similarly, we would argue that doctoral graduates should ideally be required to engage in some form of continual professional development (CPD) after graduation. For instance, graduate schools offering the doctoral training programme could create additional standalone modules (e.g., in advanced coaching practice) which graduates could be invited to attend. It could further be the case that ongoing accreditation as a positive psychologist could formally require graduates to attend a certain number of such CPD courses every few years.

In terms of the specific details of how a PP doctorate training programme might look, this is obviously something that individual graduate schools would develop according to their own 
professional judgement and local regulatory framework (i.e., the requirements of that particular country). However, as a starting point, we would like to offer the following suggestions for the type of training that such courses could feature. The following is a list of knowledge requirements (KR), core competencies (CC) and practical activities (PA) which we would ideally like to see featured in a doctorate training programme. Each could have its own module devoted specifically to it; these might be weighted at, say, 30 or 45 credits, though the weighting would be more for the KRs (e.g., 90 credits), and, of course, also the final dissertation. In addition, the KRs and CCs would ideally also be interwoven throughout all aspects of the course. Where possible, we would also argue that MAPP courses could likewise encompass all these elements, albeit obviously in a less extensive way (e.g., ethical/professional practice constituting a 15-credit rather than 45-credit module). The recommended features are:

- $\quad$ PP theory $(\mathrm{KR})$

- PP empirical research (KR)

- PP in context (e.g., in relation to other areas of psychology) (KR)

- Critical perspectives on PP (KR) / Critical thinking (CC)

- Ethical/professional practice (CC)

- Reflective practice (CC)

- Basic counselling and coaching skills (CC)

- Quantitative and qualitative methodological and analytic skills (CC)

- Professional and legal issues (e.g., establishing one's own business) (CC)

- Supervision (PA)

- Placement (a): one-to-one coaching work with an individual (PA)

- Placement (b): consulting with an organisation (e.g., company, school) (PA)

- Research project (i.e., doctoral thesis) (CC/PA).

Finally, the biggest difference between MAPP courses and this envisaged doctoral level training is that with the latter, students could be required to adhere to the ethical framework as a condition of graduation and accreditation. This, of course, would require an official body/bodies to award this kind of accreditation. Given the different regulatory landscapes in each country, we would anticipate that regulation would be instantiated and maintained by the relevant national bodies in the various countries, such as the British Psychological Society, the Australian Psychological Society, the American Psychological Association, and the Canadian Psychological Association, and so on. However, to ensure consistency across jurisdictions, ideally these national bodies could all be guided by either the IPPA or the ENPP (or ideally by both together). That is, we would hope that the IPPA and the ENPP could collaborate on a set of guidelines - perhaps along the lines of the recommendations set out in this paper - which the national bodies could then use to create their own specific regulatory framework for these doctorates. These national bodies could then be vested with authority over the way in which PP is taught and practised, as well as the power to "strike off" practitioners if they were deemed to have breached its system of ethics.

In this way, PP could join other professional psychological fields in not only having a rigorous approach to ethical training, but also having a trusted regulatory system that ensures and upholds best practice, which clients of PP can trust in. In any case, whether our proposals are taken forward, or the field adopts other sets of recommendations which are, no doubt, also forthcoming, we see it as a vital development that PP does move towards some formal, agreedupon system of ethical training and accreditation. We do not think that the suggestions outlined in this paper are the only way forward in this matter; there are different options and potential 
solutions when it comes to ethical guidelines and practice. Rather, our intention is to contribute towards a debate within the field around these important issues, with this paper being another step in the evolution of PP, helping it continue on its important mission of understanding and promoting wellbeing across the world.

\section{Authors}

Tim Lomas

University of East London

t.lomas@uel.ac.uk

Itai Ivtzan

University of East London

\section{Publishing Timeline}

Received 4 June 2016

Accepted 1 August 2016

Published 14 October 2016

\section{References}

American Psychological Association. (2010). Ethical principles of psychologists and code of conduct, with the 2010 amendments. Washington DC: Author.

Aristotle. (350 BCE/2000). Nicomachean ethics. (R. Crisp, Trans. \& Ed.). Cambridge, England: Cambridge University Press.

Belloch, A. (1997). One hundred years of clinical psychology. In R. Fuller, P. N. Walsh \& P. McGinley (Eds.), A century of psychology: Progress, paradigms and prospects for the new millennium (pp. 85-106). London, England: Routledge.

British Association for Counselling and Psychotherapy. (2010). Ethical framework for good practice in counselling and psychotherapy. Lutterworth, England: Author.

Cushway, D., \& Gatherer, A. (2003). Reflecting on reflection. Clinical Psychology, 27, 6-10.

Dilts, R. (1990). Changing belief systems with NLP. Cupertino, CA: Meta.

Edwards, J. K. (2012). Strengths-based supervision in clinical practice. New York, NY: Sage.

Fava, G. A., \& Ruini, C. (2013). Well-being therapy: Theoretical background, clinical implications, and future directions. In S. A. David, I. Boniwell \& A. C. Ayers (Eds.), The Oxford handbook of happiness (pp. 1037-1050). Oxford, England: Oxford University Press. http://dx.doi.org/10.1093/oxfordhb/9780199557257.013.0077

Finlay, F., \& Gough, B. (2003). Reflexivity: A practical guide for researchers in health and social sciences. Oxford, England: Blackwell Science. http://dx.doi.org/10.1002/9780470776094

Foster, W. (1986). A critical perspective on administration and organization in education. In K. A. Sirotnik \& J. Oakes (Eds.), Critical perspectives on the organization and improvement of schooling (pp. 95129). Dordrecht, the Netherlands: Springer. http://dx.doi.org/10.1007/978-94-009-4229-5 2

Gabriel, L. (2009). Regulation: Refusing to participate - BACP response. Therapy Today, 20(6), 34.

Gallagher, A., \& Hodge, S. (2012). Ethics, law and professional issues: A practice based approach for health professionals. Basingstoke, England: Palgrave Macmillan.

Gardner, F. (2001). Social work students and self-awareness: How does it happen? Reflective Practice, 2(1), 27-40. http://dx.doi.org/10.1080/14623940120035505

Guiffrida, D. A. (2005). The emergence model: An alternative pedagogy for facilitating self-reflection and theoretical fit in counseling students. Counselor Education and Supervision, 44(3), 201-213. http://dx.doi.org/10.1002/j.1556-6978.2005.tb01747.x 
Handelsman, M. M., Knapp, S., \& Gottlieb, M. C. (2009). Positive ethics: Themes and variations. In S. Lopez (Ed.), The handbook of positive psychology (pp. 105-113). Oxford, England: Blackwell Publishing. http://dx.doi.org/10.1093/oxfordhb/9780195187243.013.0011

Hazard Jr, G. C. (1994). Law, morals, and ethics. Southern Illinois University Law Journal, 19, 447-458.

Inskipp, F., \& Proctor, B. (1993). The art, craft and tasks of counselling supervision. New York, NY: Cascade.

Irving, J. A., Park-Saltzman, J., Fitzpatrick, M., Dobkin, P. L., Chen, A., \& Hutchinson, T. (2012).

Experiences of health care professionals enrolled in mindfulness-based medical practice: A grounded theory model. Mindfulness, 5(1), 60-71. http://dx.doi.org/10.1007/s12671-012-0147-9

Ivtzan, I., \& Lomas, T. (2016). Mindfulness in positive psychology: The science of meditation and wellbeing. London, England: Routledge.

Korthagen, F., \& Vasalos, A. (2005). Levels in reflection: Core reflection as a means to enhance professional growth. Teachers and Teaching, 11(1), 47-71. http://dx.doi.org/10.1080/1354060042000337093

Leiter, M. P., \& Maslach, C. (2005). A mediation model of job burnout. In A. S. G. Antoniou \& C. L. Cooper (Eds.), Research companion to organizational health psychology (pp. 544-564). Cheltenham, England: Edward Elgar. http://dx.doi.org/10.4337/9781845423308.00046

Linley, P. A., \& Joseph, S. (2004). Applied positive psychology: A new perspective for professional practice. In P. A. Linley \& S. Joseph (Eds.), Positive psychology in practice (pp. 3-12). Hoboken, NJ: John Wiley and Sons. http://dx.doi.org/10.1002/9780470939338

Lomas, T., Hefferon, K., \& Ivtzan, I. (2014). Applied positive psychology: Integrated positive practice. London, England: Sage.

Luft, J. (1969). Of human interactions: The Johari model. Palo Alto, CA: Mayfield.

Mackenzie, C. S., Poulin, P. A., \& Seidman-Carlson, R. (2006). A brief mindfulness-based stress reduction intervention for nurses and nurse aides. Applied Nursing Research, 19(2), 105-109. http://dx.doi.org/10.1016/j.apnr.2005.08.002

Mathenge, G. D. (2013). Ethical issues in advertising and marketing: An empirical analysis of the hindrances to efficient marketing and product communication management in Kenya. European Journal of Business and Innovation Research, 1(4), 9-19.

Mitchels, B., \& Bond, T. (2010). Essential law for counsellors and psychotherapists. Lutterworth, England: British Association for Counselling and Psychotherapy. http://dx.doi.org/10.4135/9781446288818

Muzzey, D. S. (1906). Medieval morals. International Journal of Ethics, 17(1), 29-47.

Napoli, M. (2004). Mindfulness training for teachers: A pilot program. Complementary Health Practice Review, 9(1), 31-42. http://dx.doi.org/10.1177/1076167503253435

Parks, A. C., \& Biswas-Diener, R. (2014). Positive interventions: Past, present and future. In T. Kashdan \& J. Ciarrochi (Eds.). Mindfulness, acceptance, and positive psychology: The seven foundations of well-being (pp. 140-165). Oakland, CA: New Harbinger.

Peterson, C., \& Seligman, M. E. P. (2004). Character strengths and virtues: A handbook and classification. Washington, DC: American Psychological Association.

Quality Assurance Agency for Higher Education. (2008). The framework for higher education qualifications in England, Wales and Northern Ireland August 2008. London, England: Author.

Resnick, S., Warmoth, A., \& Serlin, I. A. (2001). The humanistic psychology and positive psychology connection: Implications for psychotherapy. Journal of Humanistic Psychology, 41(1), 73-101. http://dx.doi.org/10.1177/0022167801411006

Riskin, L. L. (2004). Mindfulness: Foundational training for dispute resolution. Journal of Legal Education, 54, 79-90.

Rusk, R. D., \& Waters, L. E. (2013). Tracing the size, reach, impact, and breadth of positive psychology. The Journal of Positive Psychology, 8(3), 207-221. http://dx.doi.org/10.1080/17439760.2013.777766

Ryan, R. M., \& Deci, E. L. (2000). Self-determination theory and the facilitation of intrinsic motivation, social development, and well-being. American Psychologist, 55(1), 68-78.

http://dx.doi.org/10.1037/0003-066X.55.1.68 
Ryff, C. D. (1989). Happiness is everything, or is it? Explorations on the meaning of psychological wellbeing. Journal of Personality and Social Psychology, 57(6), 1069-1081. http://dx.doi.org/10.1037/0022$\underline{\text { 3514.57.6.1069 }}$

Sagiv, L., \& Schwartz, S. H. (2000). Value priorities and subjective well-being: Direct relations and congruity effects. European Journal of Social Psychology, 30(2), 177-198. http://dx.doi.org/10.1002/(SICI)1099-0992(200003/04)30:2<177::AID-EJSP982>3.0.CO;2-Z

Schön, D. A. (1983). The reflective practitioner: How professionals think in action. New York, NY: Basic Books.

Schwartz, S. H. (1999). A theory of cultural values and some implications for work. Applied Psychology, 48(1), 23-47. http://dx.doi.org/10.1111/j.1464-0597.1999.tb00047.x

Seligman, M. E. P. (1990). Learned Optimism. New York, NY: Pocket Books.

Seligman, M. E. P., Rashid, T., \& Parks, A. C. (2006). Positive psychotherapy. American Psychologist, 61(8), 774-788. http://dx.doi.org/10.1037/0003-066X.61.8.774

Shapiro, S. L., Brown, K. W., \& Biegel, G. M. (2007). Teaching self-care to caregivers: Effects of mindfulness-based stress reduction on the mental health of therapists in training. Training and Education in Professional Psychology, 1(2), 105-115. http://dx.doi.org/10.1037/1931-3918.1.2.105

Sheridan, S. M., Warnes, E. D., Cowan, R. J., Schemm, A. V., \& Clarke, B. L. (2004). Family-centered positive psychology: Focusing on strengths to build student success. Psychology in the Schools, 41(1), 7-17. http://dx.doi.org/10.1002/pits.10134

Soisson, E. L., Van de Creek, L., \& Knapp, S. (1987). Thorough record keeping: A good defense in a litigious era. Professional Psychology: Research and Practice, 18(5), 498-502. http://dx.doi.org/10.1037/0735-7028.18.5.498

Urry, H. L., Nitschke, J. B., Dolski, I., Jackson, D. C., Dalton, K. M., Mueller, C. J., . . Davidson, R. J. (2004). Making a life worth living: Neural correlates of well-being. Psychological Science, 15(6), 367372. http://dx.doi.org/10.1111/j.0956-7976.2004.00686.x

Vella-Brodrick, D. A. (2011). The moral of the story: The importance of applying an ethics lens to the teaching of positive psychology. The Journal of Positive Psychology, 6(4), 320-325. http://dx.doi.org/10.1080/17439760.2011.580773

Vella-Brodrick, D. A. (2014). Dovetailing ethical practice and positive psychology to promote integrity, industriousness, innovation, and impact. In A. C. Parks, \& S. M. Schueller (Eds.), The Wiley Blackwell handbook of positive psychological interventions (pp. 416-432). New York, NY: Wiley Blackwell. http://dx.doi.org/10.1002/9781118315927.ch24

Waddock, S. (2011). Finding wisdom within: The role of seeing and reflective practice in developing moral imagination, aesthetic sensibility, and systems understanding. Journal of Business Ethics Education, 7, 177-196.

Wade, J., \& Jones, J. (2013). Strength-based clinical supervision: A positive psychology approach to clinical training. New York, NY: Springer.

Wood, A. M., \& Tarrier, N. (2010). Positive clinical psychology: A new vision and strategy for integrated research and practice. Clinical Psychology Review, 30(7), 819-829.

http://dx.doi.org/10.1016/j.cpr.2010.06.003 